\title{
Prevalence of Cheyne-Stokes respiration in modern treated congestive heart failure
}

\author{
Gerrit Hagenah • Dennis Beil
}

Received: 13 April 2008 /Revised: 5 August 2008 / Accepted: 11 August 2008 / Published online: 13 September 2008

(C) The Author(s) 2008. This article is published with open access at Springerlink.com

\begin{abstract}
Introduction The prevalence of sleep breathing disorders in patients with congestive heart failure is relevantly high. According to historical studies Cheyne-Stokes respiration is an oscillatory ventilation during sleep in up to $40 \%$ of patients with congestive heart failure. During the last decade the medical treatment of congestive heart failure has been improved. The aim of this investigation was to analyze the prevalence of CheyneStokes respiration in patients with congestive heart failure and modern medical treatment.

Results and discussion In 50 patients with severe congestive heart failure receiving modern medical treatment a full night polysomnography was performed. All patients had $\beta$-blockers and angiotensin-converting-enzyme inhibitors or angiotensin-II-antagonists as standard treatment. The mean age was $63 \pm 12$ years and the mean left ventricular ejection fraction was $26 \pm 6 \%$. Respiratory polygraphy revealed Cheyne-Stokes respiration with a respiratory disturbance index of $\geq 5 / \mathrm{h}$ sleep in $32(64 \%)$
\end{abstract}

\footnotetext{
G. Hagenah

Nephrology, Department of Internal Medicine,

Georg-August-Universität,

Göttingen, Germany

D. Beil

Cardiology, Department of Internal Medicine,

Georg-August-Universität,

Göttingen, Germany

G. Hagenah $(\bowtie)$

Department of Nephrology and Rheumatology,

University of Göttingen,

Robert-Koch-Str. 40,

37075 Göttingen, Germany

e-mail: hagenah@med.uni-goettingen.de
}

of the seven female and 43 male patients. The prevalence of Cheyne-Stokes respiration defined by using the threshold of an apnea index of $\geq 10 / \mathrm{h}$ was $30 \%$.

Conclusion Thus, no significant change of Cheyne-Stokes prevalence could be found in our modern treated severe congestive heart failure collective.

Keywords Sleep disordered breathing .

Cheyne-Stokes-respiration - Congestive heart failure .

Prevalence

\section{Introduction}

For a number of years a high prevalence of sleep breathing disorders has been known to exist in patients with congestive heart failure [1-3]. Congestive heart failure is one of the leading causes of morbidity and mortality in developed countries. Since the description of a waxing and waning breathing pattern by Cheyne and Stokes the occurrence of Cheyne-Stokes respiration is well-recognized in congestive heart failure [4-5]. Several investigators showed an increased mortality in congestive heart failure combined with Cheyne-Stokes respiration [6, 7]. This possibly results from increased neurohumoral stress on the heart [8]. The treatment of congestive heart failure patients has changed during the last decade when new therapeutic standards like beta-blockers and angiotensin-convertingenzyme inhibitors have been established [9]. Prognosis of congestive heart failure patients has been improved by these new treatment standards.

The aim of this study was to find out if modern medical treatment has diminished sleep disordered breathing like Cheyne-Stokes respiration in congestive heart failure patients. 


\section{Materials and methods}

All patients with severe heart failure enrolled in the study of the Department of Cardiology at University Hospital were eligible if they met the following criteria: a left ventricular ejection fraction of $\leq 35 \%$ and at least one episode of cardiac decompensation in patient history. They all had to be in stable cardiac conditions at NYHAclassification class $2-3$ and had to have a beta-blocker and an angiotensin-converting-enzyme inhibitor or an angiotensin-II-antagonist as standard medications. No primary lung dysfunction with a forced expiratory volume in $1 \mathrm{~s}<65 \%$ was accepted for participants and no myocardial infarction should have been in the last 6 months. The patients had to be at a minimum age of 18 years. For recruitment the consecutive patients were primarily screened by echocardiographic ejection fraction and then the other criteria had to be fulfilled.

All patients provided informed consent to participate in the study, which was performed in accordance with the principles of the Declaration of Helsinki and approved by the ethics committee at the University of Goettingen. Each patient had to have a pulmonary function test as well as an electrocardiography and echocardiography.

Polysomnography was performed in one night at the sleep laboratory of the cardiology and pneumology department. No patient had a known history of sleep disordered breathing prior to our investigations. To determine the stages of sleep an electroencephalogram, a chin electromyogram and an electrooculogram were obtained. Thoracoabdominal excursions were measured with strain gauges placed on the rib cage and abdomen. Airflow was monitored with thermocouples. All polysomnographic data were collected by computer system (Alice 4, Heinen \& Löwenstein, Germany). According to the manual criteria of the American Academy of Sleep Medicine there had to be at least three cycles of crescendo and decrescendo change in breathing amplitude and five or more central sleep apneas or hypopneas per hour of sleep to be scored as Cheyne-Stokes respiration [10]. Furthermore according to the international classification of sleep disorders (ICSD-2) the apnea index (AI) of $\geq 10 / \mathrm{h}$ was defined as relevant [11]. In all patients classified as having obstructive sleep apnea or CheyneStokes respiration, that breathing disorder was the predominant pattern. Obstructive apnea or hypopnea was defined as an absence or a reduction of airflow for at least $10 \mathrm{~s}$ despite continued out-of-phase chest and abdominal movements. A mixed apnea was defined as an apnea with a combination of both central and obstructive components.

Statistical analysis was performed with SPSS (SPSS GmbH Software, Germany). The Mann-Whitney test was used to assess differences between patients with and without sleep disordered breathing, and chi-square anal- ysis was used to analyze proportions. A two-sided $P$ value of less than 0.05 was considered to indicate statistical significance. Values are reported as means.

\section{Results}

Fifty patients were included in the study (Table 1). Four of the six female and 22 of the 44 male patients had ischemic cardiomyopathy. Twenty patients had a dilated and four a hypertrophic nonobstructive cardiomyopathy. Sinus rhythm has been registered in 39 patients and arterial hypertension was prevalent in 31 patients. A documented diabetes mellitus has been observed in 14 patients, as often as nicotine abuse. More often the cardiac risk factor of hyperlipidemia were seen with 30 patients.

All of the patients were being treated with a beta-blockermedication and 42 were treated with angiotensin-convertingenzyme inhibitor while eight had angiotensin-II-antagonists. All patients were being treated with diuretic medications and 12 with digitalis. Eighteen patients received an aldosteron antagonist.

According to the mentioned American Academy of Sleep Medicine (AASM)-manual-criteria there were eight patients with a respiratory disturbance index (RDI) of less than $5 / \mathrm{h}$ and $64 \%$ of all study patients had Cheyne-Stokes breathing patterns (Table 2). Twenty-two (44\%) of all patients had a Cheyne-Stokes respiration with an AHI $>15 / \mathrm{h}$. Ten patients (20\%) had mainly obstructive sleep breathing disorders during sleep.

If ICSD-2-criteria for sleep investigations were used there would have been 34 patients (68\%) with an AI of less than 10/h. Fifteen $(30 \%)$ of all patients had a Cheyne-Stokes respiration with an $\mathrm{AI} \geq 10 / \mathrm{h}(25 \pm 13$ vs $4 \pm 10, p<0.0001)$.

Considering cardiac characteristics of all patients the mean ejection fraction was $26 \pm 6 \%$ and the average left ventricular diastolic dimension was $64 \pm 8 \mathrm{~mm}$. Mean septal dimension was $11 \pm 2 \mathrm{~mm}$ and left atrial dimension was $49 \pm$ $8 \mathrm{~mm}$. Divided into patient groups with and without

Table 1 Clinical data of the patients

\begin{tabular}{lcccl}
\hline Variable & $\begin{array}{l}\text { Patients } \\
(n=50)\end{array}$ & $\begin{array}{l}\text { CSR } \\
(n=32)\end{array}$ & $\begin{array}{l}\text { NCSR } \\
(n=18)\end{array}$ & $P$ value \\
\hline Age (years) & $63 \pm 12$ & $62 \pm 13$ & $63 \pm 12$ & $\mathrm{~ns}$ \\
Body mass index $\left(\mathrm{kg} / \mathrm{m}^{2}\right)$ & $26.6 \pm 4.3$ & $26.3 \pm 3.7$ & $27.1 \pm 5.3$ & $\mathrm{~ns}$ \\
Height $(\mathrm{cm})$ & $175 \pm 10$ & $177 \pm 9$ & $172 \pm 10$ & 0.1 \\
Heart rate (bpm) & $74 \pm 18$ & $75 \pm 18$ & $70 \pm 18$ & $\mathrm{~ns}$ \\
FEV1/VC (\% standard) & $102 \pm 16$ & $102 \pm 14$ & $101 \pm 19$ & $\mathrm{~ns}$ \\
\hline
\end{tabular}

CSR patients with Cheyne-Stokes respiration according to AASMmanual-criteria, NCSR non Cheyne-Stokes respiration patients, ns non-significant, $F E V 1 / V C \%$ Standard forced exspiratory volume in 1 second/vitalcapacity in percent of standard value 
Table 2 Characteristics of the patients during sleep

\begin{tabular}{lccl}
\hline Variable & CSR $(n=32)$ & NCSR $(\mathrm{n}=18)$ & $P$ value \\
\hline Total sleep time (min) & $314 \pm 62$ & $297 \pm 100$ & $\mathrm{~ns}$ \\
NonREM (min) & $280 \pm 55$ & $254 \pm 79$ & $\mathrm{~ns}$ \\
REM (min) & $50 \pm 29$ & $53 \pm 28$ & $\mathrm{~ns}$ \\
RDI (/h TST) & $26 \pm 16$ & $10 \pm 14$ & 0.001 \\
AHI (/h) & $23 \pm 15$ & $8 \pm 14$ & 0.001 \\
Apnea-index (/h sleep) & $13 \pm 14$ & $5 \pm 14$ & 0.04 \\
Arousal-index (/h sleep) & $25 \pm 15$ & $29 \pm 17$ & $\mathrm{~ns}$ \\
Mean oxygen saturation (\%) & $89 \pm 4$ & $90 \pm 3$ & $\mathrm{~ns}$ \\
Min. oxygen saturation (\%) & $81 \pm 7$ & $84 \pm 8$ & $\mathrm{~ns}$ \\
\hline
\end{tabular}

CSR patients with Cheyne-Stokes respiration according to AASMmanual-criteria, NCSR non Cheyne-Stokes respiration patients, TST total sleep time, $R E M$ rapid eye movement sleep, $R D I$ respiratory disturbance index, $A H I$ apnea-hypopnea index, $n s$ non-significant

Cheyne-Stokes respiration according to AASM-manualcriteria the only significant difference was the septal dimension regardless of the kind of sleep disorders cutoff point (Table 3). For ICSD-2-criteria there was a tendency to a worse ejection fraction in patients suffering from CheyneStokes respiration $(\mathrm{p}<0.1)$.

\section{Discussion}

Cheyne-Stokes respiration has been common during sleep in congestive heart failure patients in previously published investigations $[1-3,12]$. There are also hints for a poorer prognosis in those congestive heart failure patients with Cheyne-Stokes respiration [6, 7, 13]. Modern medical treatment has a prognostic impact in patients with congestive heart failure [14-19]. In a small study population of 8 patients Walsh and colleagues showed a reduction of apneic episodes as well as arousals and an increase of slow wave and REM sleep by treatment with captopril [20]. More recent studies by Koehnlein and colleagues as well as Tamura and colleagues stated a reduced prevalence in ß-blocker-treated heart failure patients [21, 22]. Both investigations failed to request equal baseline therapy according to treatment guidelines.

In this investigation modern medication standards like beta-blockers and angiotensin-converting-enzyme inhibitors or angiotensin-II-antagonists showed no beneficial influence in the prevalence of Cheyne-Stokes respiration. As a limitation no own control data were used.

While there are widely accepted standards for analyses of sleep apnea the definition of Cheyne-Stokes respiration is less precise. If the actual AASM-manual-criteria of sleep breathing disorders with a cutoff respiratory disturbance index of $\geq 5 / \mathrm{h}$ would have been used, the incidence would be $64 \%$. These results are almost similar to the retrospective study results of Sin et al. in 450 patients with an occurrence of sleep breathing disorders of $72 \%, 61 \%$, and $53 \%$ according to an apnea-hypopnea index cutoff point of 10 , 15 , and $20 / \mathrm{h}$ in congestive heart failure patients [3]. Still in that earlier study no standard medical treatment was given as recommended by modern heart failure treatment guidelines [9]. As the respiratory disturbance index is attributed to the total sleep time [23], it tends to be higher than the apneahypopnea index related to the total recording time in bed [7]. This termination has not been standardized so far, therefore an apnea-hypopnea index could have been related to timein-bed or total sleep time in earlier investigations [2, 7, 24]. Furthermore the ICSD- 2 definitions recommend an $\mathrm{AI} \geq 10$ / $\mathrm{h}$ for Cheyne-Stokes respiration [11]. According to this definition there would be a lower number of patients with Cheyne-Stokes respiration in our study population, still this definition would not be comparable to previous studies.

In 203 German patients with congestive heart failure and left ventricular ejection fraction $<40 \%$ an apnea-hypopnea index cutoff about $10 / \mathrm{h}$ were seen by polysomnography in $71 \%$ with a majority in obstructive sleep apnea probably due to higher body mass index [25]. The prevalence of sleep breathing disorders according to common study criteria with an apnea-hypopnea index cutoff about $10 / \mathrm{h}$ and $15 / \mathrm{h}$ is approximately $56 \%$ and $48 \%$ in our study population. The prevalence in the historic collective of Javaheri et al. with an apnea-hypopnea index cutoff about $15 / \mathrm{h}$ has been about $50 \%$ for sleep breathing disorders [2].

Compared to the prevalence in the study population of Javaheri et al. the prevalence of Cheyne-Stokes respiration in the sleep breathing disorders was between $66 \%$ and $44 \%$ in our patients group depending on the cutoff versus $40 \%$ in Javaheri's patient group. The different inclusion criteria concerning the ejection fraction of $<45 \%$ in Javaheris study and $\leq 35 \%$ in our study may be the reason for the small difference.

A retrospective analyses in 450 consecutive patients with congestive heart failure with an apnea-hypopnea index cutoff about $10 / \mathrm{h}$ found a prevalence of sleep breathing disorders of $72 \%$ [3]. In that retrospective analyses the prevalence of Cheyne-Stokes respiration of $33 \%$ was comparable to the

Table 3 Cardiac characteristics of the patients

\begin{tabular}{llll}
\hline Variable & CSR $(n=32)$ & Non-CSR $(n=18)$ & $P$ value \\
\hline Ejection fraction (\%) & $26.3 \pm 6.3$ & $25.8 \pm 6.7$ & $\mathrm{~ns}$ \\
LVEDD (mm) & $65.1 \pm 8.0$ & $61.4 \pm 8.4$ & $\mathrm{~ns}$ \\
Left atrial dimension (mm) & $50.1 \pm 8.0$ & $48.2 \pm 7.9$ & $\mathrm{~ns}$ \\
Septal dimension (mm) & $11.9 \pm 2.3$ & $10.6 \pm 1.9$ & $<0.05$ \\
Remained sinus rhythm & 24 & 15 & $\mathrm{~ns}$ \\
Bundle brunch block & 17 & 11 & $\mathrm{~ns}$ \\
\hline
\end{tabular}

CSR patients with Cheyne-Stokes respiration according to AASMmanual-criteria, Non-CSR non Cheyne-Stokes respiration patients, $L V E D D$ left ventricular enddiastolic dimension, $n s$ non-significant 
German patients with $28 \%$ [25]. The differences to our as well as Javaheris findings are possibly related to a higher body mass index leading to an increased prevalence of obstructive sleep apneas as well as no predefined inclusion ejection fraction in Sins' patient collective.

Although the modern medical treatment improved prognostic outcome in congestive heart failure there appears to be no clear evidence of a reduction in CheyneStokes respiration. The increasing prevalence of chronic heart failure is affecting patients' quality of life, and health resources, despite advances in management. Recognizing and treating comorbid illnesses is critical. Risk factors such as hypertension and diabetes are treated, but less importance is placed on the role of sleep apnea in heart failure. Apneic episodes during sleep can lead to profound disturbances to the sympathetic and parasympathetic nervous system.

\section{Conclusions}

In conclusion special therapeutic strategies in Cheyne-Stokes respiration may still be of importance for further prognostic benefit in congestive heart failure patients. There is no clear evidence for a reduction of Cheyne-Stokes respiration due to modern medical treatment in congestive heart failure.

Competing interests The authors declare that they have no competing interests.

Open Access This article is distributed under the terms of the Creative Commons Attribution Noncommercial License which permits any noncommercial use, distribution, and reproduction in any medium, provided the original author(s) and source are credited.

\section{References}

1. Findley LJ, Zwillich CW, Anconi-Israel S, Kripke D, Moser KM (1985) Cheyne-Stokes breathing during sleep in patients with left ventricular heart failure. South Med J 78(1):11-15

2. Javaheri S, Parker TJ, Liming JD, Corbett WS, Nishiyama H, Wexler L et al (1998) Sleep apnea in 81 ambulatory male patients with stable heart failure. Types and their prevalences, consequences, and presentations. Circulation 97(21):2154-2159

3. Sin DD, Fitzgerald F, Parker JD, Newton G, Floras JS, Bradley TD (1999) Risk factors for central and obstructive sleep apnea in 450 men and women with congestive heart failure. Am J Respir Crit Care Med 160(4):1077-1078

4. Cheyne J (1818) A case of apoplexy in which the fleshy part of the heart is turned to fat. Dublin Hosp Rep 2:216-223

5. Stokes W (1854) The diseases of the heart and the aorta. Hodges and Smith, Dublin, pp 323-326
6. Hanly PJ, Zuberi-Khokhar NS (1996) Increased mortality associated with Cheyne-Stokes respiration in patients with congestive heart failure. Am J Respir Crit Care Med 153(1):272-276

7. Lanfranchi PA, Braghiroli A, Bosimini E, Mazzero G, Colombo R, Donner CF et al (1999) Prognostic value of nocturnal CheyneStokes respiration in chronic heart failure. Circulation 99 (11): $1435-1440$

8. Köhnlein T, Welte T, Tan LB, Elliott MW (2002) Central sleep apnoea syndrome in patients with chronic heart disease: a critical review of the current literature. Thorax 57(6):547-554 doi:10.1136/thorax.57.6.547

9. McMurray J, Swedberg K (2006) Treatment of chronic heart failure: a comparison between the major guidelines. Eur Heart J 27:1773-1777 doi:10.1093/eurheartj/ehl123

10. Iber C, Ancoli-Israel S, Chesson AL Jr, Quan SF (2007) The AASM Manual for the Scoring of Sleep and Associated Events: Rules, Terminology and Technical Specifications. AASM Manual for Scoring Sleep

11. American Academy of Sleep Medicine (2005) ICSD-2 International classification of sleep disorders, 2nd edn: Diagnostic and coding manual. Westchester, Illinois, USA

12. Lofaso F, Verschueren P, Rande JLD, Harf A, Goldenberg F (1994) Prevalence of sleep-disordered breathing in patients on a heart transplant waiting list. Chest 106(6):1689-1694 doi:10.1378/chest.106.6.1689

13. Andreas S, Hagenah G, Möller C, Werner GS, Kreuzer H (1996) Cheyne-Stokes respiration and prognosis in congestive heart failure. Am J Cardiol 78(11):1260-1264 doi:10.1016/S00029149(96)00608-X

14. Gruppo Italiano per lo Studio della Sopravvivenza nell Infarcto Miocardico (1994) GISSI-3: Effects of lisinopril and transdermal glyceryl trinitrate singly and together on 6-week mortality and ventricular function after acute myocardial infarction. Lancet 343:1115-1122

15. Cohn JN, Tognoni G (2001) Valsartan heart failure trial investigators: a randomized trial of the angiotensin-receptor blocker valsartan in chronic heart failure. N Engl J Med 345:1667-1675 doi:10.1056/NEJMoa010713

16. The SOLVD Investigators (1991) effect of Enalapril on survival in patients with reduced left ventricular ejection fractions and congestive heart failure. N Engl J Med 325:293-302

17. CIBIS-II Investigators and Committees (1999) The cardiac insufficiency bisoprolol study (CIBIS-II): a randomised trial. Lancet 353:9-13 doi:10.1016/S0140-6736(98)11181-9

18. MERIT-HF Study Group (1999) Effect of metoprolol CR/XL in chronic heart failure: Metoprolol CR/XL randomised intervention trial in congestive heart failure. Lancet 353:2001-2007 doi:10.1016/S0140-6736(99)04440-2

19. Pitt B, Poole-Wilson PA, Segal R, Martinez FA, Dickstein K, Camm AJ et al (2000) Effect of losartan compared with captopril on mortality in patients with symptomatic heart failure. A randomised trial - the losartan heart failure survival study ELITE II. Lancet 355:1582-1587 doi:10.1016/S0140-6736(00) 02213-3

20. Walsh JT, Andrews R, Starling R, Starling AJ, Johnston ID, Kinnear WJ (1995) Effects of captopril and oxygen on sleep apnoea in patients with mild to moderate congestive cardiac failure. Br Heart J 73(3):237-241 doi:10.1136/hrt. 73.3.237

21. Kohnlein T, Welte T (2007) Does beta-blocker treatment influence central sleep apnoea? Respir Med 101:850-853 doi:10.1016/j. rmed.2006.11.023

22. Tamura A, Kawano Y, Naono S, Kotoku M, Kadota J (2007) Relationship between B-blocker treatment and the severity of 
central sleep apnea in chronic heart failure. Chest 131:130135 doi:10.1378/chest.06-0919

23. Kinsman TA, Townsend NE, Gore CJ, Hahn AG, Clark SA, Aughey RJ et al (2005) Sleep disturbance at simulated altitude indicated by stratified respiratory disturbance index but not hypoxic ventilatory response. Eur J Appl Physiol 94:569-575 doi:10.1007/s00421-005-1368-6
24. Fietze I, Dingli K, Diefenbach K, Douglas NJ, Glos M, Tallafuss $\mathrm{M}$ et al (2004) Night-to-night variation of the oxygen desaturation index in sleep apnoea syndrome. Eur Respir J 24:987-993 doi:10.1183/09031936.04.00100203

25. Schulz R, Blau A, Borgel J, Duchna HW, Fietze I, Koper I et al (2007) Sleep apnoea in heart failure. Eur Respir J 29 (6):1201-1205 doi:10.1183/09031936.00037106 